Foudah et al., Afr J Tradit Complement Altern Med., (2017) 14 (5): 31 -40

https://doi.org/10.21010/ajtcam.v14i5.5

\title{
ANTIOXIDANT AND HEPATOPROTECTIVE EFFECTS OF ASTRAGALUS ECHINOPS AND ASTRAGALUS LOGOPODIOIDES ETHANOLIC EXTRACTS ON PARACETAMOL-INDUCED LIVER INJURY IN RATS
}

\author{
Ahmed I. Foudah ${ }^{1}$, Gamal A. Soliman ${ }^{2,3}$, Rehab F. Abdel-Rahman ${ }^{4}$, Özgen Alankuş- Çalışkan ${ }^{5}$, Hasan \\ Yusufoglu ${ }^{1, *}$
}

${ }^{1}$ Department of Pharmacognosy, College of Pharmacy, Prince Sattam bin Abdulaziz University, Al-Kharj, KSA. ${ }^{2}$ Department of Pharmacology, College of Pharmacy, Prince Sattam bin Abdulaziz University, Al-

Kharj, KSA. ${ }^{3}$ Department of Pharmacology, College of Vet Med, Cairo University, Cairo, Egypt.

${ }^{4}$ Department of Pharmacology, National Research Centre, Cairo, Egypt. ${ }^{5}$ Deapartment of Chemistry, Faculty of Science, Ege University, Bornova, İzmir, 35100, Turkey

*Corresponding Author E-mail: hasanagazar@hotmail.com ; h.yusufoglu@ sau.edu.sa

\begin{tabular}{|c|}
\hline \multicolumn{1}{|c|}{ Article History } \\
Received: 22, Jan. 2017 \\
Revised Received: 24, April. 2017 \\
Accepted: 24, April. 2017 \\
Published Online: 01 , Oct. 2017 \\
\hline
\end{tabular}

Abstract

Background: Paracetamol (PCM) has an adequate safety profile when taken in normal doses. However, it could produce oxidative stress with liver injury when taken in an overdose. Plants of Astragalus genus (F. Fabaceae) are of wide-spread applications. Astragalus echinops (A. echinops) and Astragalus logopodioides (A. logopodioides) were tested for their potential hepatoprotective activities against liver injury induced by PCM in rats.

Material and Methods: Seven groups of rats were used for determination of hepatoprotective activities of the extracts. The normal and hepatotoxic control groups received the vehicle while other groups were treated with silymarin (100 $\mathrm{mg} / \mathrm{kg}$ ), A. echinops (250 and $500 \mathrm{mg} / \mathrm{kg}$ ) and A. logopodioides (250 and $500 \mathrm{mg} / \mathrm{kg}$ ), respectively for seven days. Liver injury was induced on the $5^{\text {th }}$ day by oral dosing of PCM $(2 \mathrm{~g} / \mathrm{kg})$ to all rats except those in normal control group. Moreover, the in vitro antioxidant activities of A. echinops and A. logopodioides extracts were tested using 2,2diphenyl-1-picryl-hydrazyl (DPPH) radical scavenging.

Results: Hepatic enzyme markers as alanine aminotransferase, aspartate aminotransferase, alkaline phosphatase and glutamyl transferase and level of total bilirubin were significantly elevated, while total protein and albumin were declined significantly in PCM-exposed animals. The liver antioxidant markers like the activities of superoxide dismutase, catalase and glutathione peroxidase and the levels of reduced glutathione were significantly declined, while hepatic malondialdehyde levels were significantly increased in PCM alone-treated rats. Administration of A. echinops $(250$ and $500 \mathrm{mg} / \mathrm{kg}$ ) and $A$. logopodioides $(500 \mathrm{mg} / \mathrm{kg}$ ) extracts prior to PCM, significantly protected against the elevation in the serum activities of hepatic enzymes and bilirubin and reduced oxidative stress. The hepatoprotective effect of both extracts was further confirmed by histological findings in the liver tissue. In addition, both extracts displayed in vitro antioxidant activities in a concentration-dependent way.

Conclusion: Our results suggest that both extracts protect the liver against oxidative damage and they could be used as effective hepatoprotectives against PCM induced liver injury.

Keywords: Astragalus, Paracetamol, Hepatotoxicity, Hepatoprotective, DPPH, Antioxidant.

\section{Introduction}

The liver is the key organ of biotransformation and elimination. It is mostly subjected to a set of toxicants and therapeutic agents. Chemical-provoked hepatotoxicity can imitate all forms of liver diseases. The generality of the hepatotoxic agents injures hepatocytes mainly by causing lipid peroxidation (LPO) and other oxidative stress (Handa et al., 1989). At therapeutic doses, PCM (N-acetyl-p-aminophenol) is used as an effective analgesic and antipyretic agent. However, the overdose of PCM can induce severe liver injury and liver necrosis. The adverse effect of PCM is mediated by the action of its reactive metabolite known as $N$-acetyl- $p$-benzoquinone imine (NAPQI). An elevated level of NAPQI mediates oxidative damage, and therefore consolidates tissue damages and organ dysfunction, including liver injury (Hinson et al., 2010). Das et al. (2010) suggested that hepatotoxicity induced by PCM is mediated by 
oxidative damage. Thus, the alternative therapy for PCM toxicity could be accomplished, using a natural product with antioxidant activity.

Astragalus L. is believed as the largest genus of the family Fabaceae with approximately 2500-3000 species (Podlech, 2008). Plants of Astragalus genus is widely distributed throughout the temperate areas of the world. Most of these plants are found in the arid, continental areas of western North America and central Asia. The roots and leaves of some Astragalus plants are used for the treatment of gastric ulcer, cough, bronchitis, increased blood pressure and gynecological disorders (Benchadi et al., 2013). Roots of some Astragalus plants have shown different medicinal activities including hepatoprotective, immunostimulant, and antiviral actions (Pistelli 2002). The genus Astragalus is known to be a rich source of bioactive compounds. Previous phytochemical studies reported that Astragalus plants accumulate three main groups of biologically active compounds-polysaccharides, flavonoids, and saponins (Pistelli et al., 2003). Furthermore, Bagheri et al. (2015) mentioned that the genus Astragalus is well documented as an interesting source of biologically active substances such as phenolics, triterpenoid saponins, flavonoids, and polysaccharides. In this study, we determined the potential antioxidant activities and the protective effects of A. echinops and A. logopodioides extracts against PCM-induced hepatotoxicity.

\section{Material and Methods Plant materials}

Roots of A. echinops and A. logopodioides were collected from Van: Çatak, Kurulu village, up to old army union, 1700-2100 m altitude and Van: Hoşap, between Bakımevi-Fedai Taş, $2950 \mathrm{~m}$ altitude, respectively, East Anatolia, Turkey in June 2010, and identified by Assoc. Prof. Dr. Fevzi Özgökçe (Department of Biology, Faculty of Science and Art, Yüzüncü Y1l University, Van, Turkey). Voucher specimens have been deposited in the Herbarium of Yüzüncü Y1l University, Van, Turkey, Herbarium no: (VANF 13741) and (VANF 13747) respectively.

\section{Plant extraction}

The collected roots were shade dried, grinded to fine powders and extracted with $80 \%$ aqueous ethanol $(2 \times 3$ L) under reflux. The ethanolic extracts of A. echinops and A. logopodioides were subjected to rotary evaporation $\left(70 \pm 2^{\circ} \mathrm{C}\right)$ and lyophilized using freeze dryer to yield 20.4 and $16.8 \mathrm{~g}$, respectively.

\section{Experimental animals}

Forty-two male Wistar rats of 180-200 g body weights were used in the present investigation. Rats were bred in Lab Animal Care Unit, Pharmacy College, Prince Sattam bin Abdulaziz University, Al-Kharj, KSA. Rats were kept under standard environmental conditions (temperature $23 \pm 2{ }^{\circ} \mathrm{C}$ and 12 -h light/ dark cycle). The animals were fed with standard rat pellets and water ad libitum and acclimatized to laboratory conditions for 7 days before conducting experiments. Experimental procedures were done in accordance with international regulations on animal protection, and/or the Guide for the Care and Use of Laboratory Animals. The study protocol was approved by the Institutional Animal Ethics Committee.

\section{Acute toxicity in rats}

To test the acute toxicity of $A$. echinops $A$. and logopodioides extracts, three groups of rats were used $(n=6)$ according to OECD-423 guidelines (OECD, 2001). Both extracts were suspended in the vehicle (3\% v/v Tween 80 in distilled water). Rats of the 1 st and 2 nd groups received the ethanolic extracts of A. echinops and A. logopodioides, respectively at an oral dose of $5000 \mathrm{mg} / \mathrm{kg}(5 \mathrm{~mL} / \mathrm{kg})$. Rats of the $3 \mathrm{rd}$ group (control) medicated with the vehicle and kept under the same situations. Rats were observed for mortalities or signs of toxicity during the first $30 \mathrm{~min}$ and periodically during $24 \mathrm{~h}$, with special attention given during the first four hours and thereafter, daily for a total of 14 days.

\section{Selection of doses}

After oral administration of $A$. echinops $A$. and logopodioides extracts in an acute toxicity test, no mortalities were reported up to $5000 \mathrm{mg} / \mathrm{kg}$, and hence $1 / 20^{\text {th }}$ and $1 / 10^{\text {th }}$ of the highest dose administered (i.e., $250 \mathrm{and} 500 \mathrm{mg} / \mathrm{kg}$, respectively) were selected for the present study.

\section{Hepatoprotective activity Experimental Design}

Forty-two mature male Wistar rats (180-200 g body weight) were randomly divided into seven equal groups. Rats of the $1^{\text {st }}$ and $2^{\text {nd }}$ groups (normal control and PCM-hepatotoxic control, respectively) were provided with the vehicle at $5 \mathrm{~mL} / \mathrm{kg}$. Rats of the $3^{\text {rd }}$ group received silymarin at $100 \mathrm{mg} / \mathrm{kg}$ (Reference group). Animals of the $4^{\text {th }}$ and $5^{\text {th }}$ groups received the ethanolic extract of $A$. echinops at 250 and $500 \mathrm{mg} / \mathrm{kg}$, respectively. The $6^{\text {th }}$ and $7^{\text {th }}$ groups received A. logopodioides extract at 250 and $500 \mathrm{mg} / \mathrm{kg}$, respectively. Administration of the vehicle and test extracts was made 
daily by oral gavage for 7 days. Hepatotoxicity was induced on the $5^{\text {th }}$ day by oral administration of PCM ( $\left.2 \mathrm{~g} / \mathrm{kg}\right)$ to all the rats except those in the $1^{\text {st }}$ group.

\section{Serum preparation}

On the $7^{\text {th }}$ day, two hours after treatments, blood samples were obtained via retro-orbital sinus plexus. Blood samples were left at room temperature to clot and sera were obtained by centrifugation at $4000 \mathrm{rpm}$ for $15 \mathrm{~min}$ and maintained at $-20^{\circ} \mathrm{C}$ until further biochemical analysis.

\section{Tissue Collection}

Immediately following blood collection, all animals were euthanized and livers were separated from the surrounding tissue and divided into two halves.

\section{Preparation of liver homogenate}

The first portion of each liver was weighted and washed using ice cold PBS (phosphate buffer saline) then homogenized in phosphate buffer $(25 \mathrm{mM}, \mathrm{pH} 7.4)$ to produce an approximately $10 \% \mathrm{w} / \mathrm{v}$ homogenate. Liver homogenates were centrifuged at $1700 \mathrm{rpm}$ for $10 \mathrm{~min}$ and the supernatants were collected and maintained at $-20^{\circ} \mathrm{C}$ until subsequent biochemical analysis.

\section{The effects on serum biochemical parameters}

Serum activities of alanine aminotransferase (ALT), aspartate aminotransferase (AST), alkaline phosphatase (ALP) and glutamyl transferase $(\gamma-\mathrm{GT})$ and level of total protein (TP), albumin (ALB) and total bilirubin (BRN) were evaluated according to the instructor manual of commercially available kits.

\section{The effects on PCM-induced oxidative stress}

The activities of the antioxidant enzymes like superoxide dismutase (SOD), catalase (CAT) and glutathione peroxidase $(\mathrm{GPx})$ and the levels of reduced glutathione (GSH) malondialdehyde (MDA) were estimated in liver homogenates of rats according to the instructor manual of commercially available kits.

\section{Histopathological Examination}

The second portion of each liver was fixed in 10-percent (w/v) buffered formalin. The fixed tissues were embedded in paraffin, and then slices of $5 \mu \mathrm{m}$ thickness were cut off. The slices of the livers were stained with hematoxylin and eosin (H \& E) and evaluated for the pathological changes of hepatotoxicity.

\section{In vitro antioxidant activity}

In an attempt to estimate the antioxidant potential of $A$. echinops and A. Logopodioides extracts, the DPPH free radical scavenging assay was used (Phang et al., 2011). A solution of 2,2-Diphenyl-1-picrylhydrazyl radical (DPPH) in methanol $(0.004 \%$ solution) was prepared and stored in dark until use. Preparations of the tested extracts at different concentrations were done in methanol. In a 96-well plate, an addition of $20 \mu \mathrm{l}$ of each concentration to $180 \mu \mathrm{DPPH}$ solution was carried out. Negative controls were done to correct for colored extracts. The consequent reaction mixtures were mixed and incubated at room temperature for $30 \mathrm{~min}$. The absorbance of the reaction mixtures was measured at $520 \mathrm{~nm}$. Methanol was used as blank and a solution of DPPH was served as control. Ascorbic acid and pyrogallol were used as positive controls. The scavenging activities were calculated according to the equation:

$$
\text { Scavenging activity }(\%)=\frac{(A \text { control }-A \text { sample })}{A \text { control }} \times 100
$$

Where A control is the absorbance of the control reaction with $50 \mu \mathrm{L}$ deionized water without the extract or ascorbic acid, and A sample is the absorbance in the presence of the sample. The values of $\mathrm{EC}_{50}$ were calculated according to the graph of percentage of inhibition plotted against the concentration of the tested extract. $\mathrm{EC}_{50}$ is defined as the amount of extract needed to scavenge $50 \%$ of DPPH radicals.

\section{Statistical analysis}

Data are expressed as the mean \pm standard error of six observations in each group. Our results were subjected to one-way analysis of variance (ANOVA) followed by Dunnett's test to determine the intergroup variability by using SPSS ver. 14.0. A comparison was made with the normal control and PCM-hepatotoxic groups. We took a P-value of $<0.05$ as the desired level of significance. 


\section{Results}

\section{Acute toxicity study}

Ethanolic extracts of $A$. echinops $A$. and logopodioides at a dose of $5000 \mathrm{mg} / \mathrm{kg}$ had no adverse effect on the behavioral responses of the tested rats up to 14 days of observation. At $5000 \mathrm{mg} / \mathrm{kg}$, there was no mortality observed in rats throughout the experimental period. Therefore, the extract seems to be safe at a dose level of $5000 \mathrm{mg} / \mathrm{kg}$, and the $\mathrm{LD}_{50}$ was considered be $>5000 \mathrm{mg} / \mathrm{kg}$.

\section{Hepatoprotective activity}

\section{The effects on serum biochemical parameters}

Serum activities of ALT, AST, ALP and $\gamma$-GT were estimated as the biochemical markers of liver damage.

Table 1: Effect of A. echinops and A. logopodioides extracts on the serum activity of liver marker enzymes in rats with PCM- induced hepatotoxicity.

\begin{tabular}{|l|c|c|c|c|}
\hline \multicolumn{1}{|c|}{ Treatments } & $\begin{array}{c}\text { ALT } \\
(\mathbf{U} / \mathbf{L})\end{array}$ & $\begin{array}{c}\text { AST } \\
(\mathbf{U} / \mathbf{L})\end{array}$ & $\begin{array}{c}\text { ALP } \\
(\mathbf{U} / \mathbf{L})\end{array}$ & $\begin{array}{c}\gamma-\mathbf{G T} \\
(\mathbf{U} / \mathbf{L})\end{array}$ \\
\hline Normal Control & $12.8 \pm 0.16 \#$ & $116.4 \pm 4.64 \#$ & $57.8 \pm 2.12 \#$ & $34.3 \pm 1.54 \#$ \\
\hline PCM-hepatotoxic Control & $29.4 \pm 1.27 \phi$ & $328.2 \pm 22.78 \phi$ & $104.1 \pm 4.14 \phi$ & $68.5 \pm 2.75 \phi$ \\
& $(129.68 \%)$ & $(181.95 \%)$ & $(80.10 \%)$ & $(99.70 \%)$ \\
\hline Silymarin $(100 \mathrm{mg} / \mathrm{kg})+\mathrm{PCM}$ & $13.2 \pm 0.29 \#$ & $124.4 \pm 5.32 \#$ & $63.8 \pm 2.27 \#$ & $38.8 \pm 1.74 \#$ \\
& $(-55.10 \%)$ & $(-62.09 \%)$ & $(-38.71 \%)$ & $(-43.35 \%)$ \\
\hline A. echinops $(250 \mathrm{mg} / \mathrm{kg})+\mathrm{PCM}$ & $19.8 \pm 0.31 \phi \#$ & $166.5 \pm 6.65 \phi \#$ & $81.0 \pm 3.15 \phi \neq$ & $49.5 \pm 1.32 \phi \#$ \\
& $(-32.65 \%)$ & $(-49.26 \%)$ & $(-22.19 \%)$ & $(-27.73 \%)$ \\
\hline A. echinops $(500 \mathrm{mg} / \mathrm{kg})+\mathrm{PCM}$ & $17.6 \pm 0.22 \phi \#$ & $147.2 \pm 4.82 \phi \#$ & $70.6 \pm 2.97 * \#$ & $42.2 \pm 0.95 * \#$ \\
& $(-40.13 \%)$ & $(-55.14 \%)$ & $(-32.18 \%)$ & $(-38.39 \%)$ \\
\hline A. logopodioides $(250 \mathrm{mg} / \mathrm{kg})+\mathrm{PCM}$ & $25.7 \pm 1.15 \phi$ & $268.7 \pm 19.41 \phi$ & $97.2 \pm 3.61 \phi$ & $61.4 \pm 2.42 \phi$ \\
& $(-12.58 \%)$ & $(-18.12 \%)$ & $(-6.62 \%)$ & $(-10.36 \%)$ \\
\hline A. logopodioides $(500 \mathrm{mg} / \mathrm{kg})+\mathrm{PCM}$ & $20.0 \pm 0.38 \phi \#$ & $215.8 \pm 5.28 \phi \#$ & $85.4 \pm 3.29 \phi *$ & $50.0 \pm 1.20 \phi \#$ \\
& $(-31.97 \%)$ & $(-34.24 \%)$ & $(-17.96 \%)$ & $(-27.00 \%)$ \\
\hline
\end{tabular}

Values explain the mean \pm S.E. of seven animals per group.

* $\mathrm{P}<0.05$ : Statistically significant from normal control (Dunnett's test). $\phi \mathrm{P}<0.001$ : Statistically significant from normal control (Dunnett's test).

$\cdot \mathrm{P}<0.05$ : Statistically significant from PCM-hepatotoxic control (Dunnett's test).

\# P< 0.001: Statistically significant from PCM-hepatotoxic control (Dunnett's test).

As shown in Table 1, the activities of ALT, AST, ALP and $\gamma$-GT in serum were dramatically elevated (129.68, $181.95,80.10$ and $99.70 \%$, respectively) after PCM overdose in comparison with the normal control group. Moreover, pre-treatment of the PCM-exposed rats with A. echinops (250 and $500 \mathrm{mg} / \mathrm{kg}$ ) or A. logopodioides (500 mg/kg) extracts significantly inhibited the elevations in the levels of liver enzymes in PCM-treated rats in a dose-dependent way. In addition, silymarin $(100 \mathrm{mg} / \mathrm{kg})$ showed the capability to antagonize the toxic effect of PCM by significantly reducing the level of liver enzymes in comparison to the PCM-intoxicated group.

Table 2: Effect of A. echinops and A. logopodioides extracts on the serum levels of TP, ALB, and BRN in rats with PCM- induced hepatotoxicity.

\begin{tabular}{|c|c|c|c|}
\hline Treatments & $\begin{array}{c}\text { BRN } \\
(\mathrm{mg} / \mathrm{dL})\end{array}$ & $\begin{array}{c}\mathbf{T P} \\
(\mathrm{g} / \mathrm{dL})\end{array}$ & $\begin{array}{c}\text { ALB } \\
(\mathrm{g} / \mathrm{dL})\end{array}$ \\
\hline Normal Control & $0.5 \pm 0.05 \#$ & $7.8 \pm 0.21 \#$ & $3.6 \pm 0.11 \#$ \\
\hline PCM-hepatotoxic Control & $\begin{array}{l}1.4 \pm 0.09 \phi \\
(180.00 \%)\end{array}$ & $\begin{array}{l}5.3 \pm 0.18 \phi \\
(-32.05 \%)\end{array}$ & $\begin{array}{l}2.4 \pm 0.09 \phi \\
(-33.33 \%)\end{array}$ \\
\hline Silymarin $(100 \mathrm{mg} / \mathrm{kg})+\mathrm{PCM}$ & $\begin{array}{c}0.7 \pm 0.07 * \# \\
(-50.00 \%)\end{array}$ & $\begin{array}{l}7.2 \pm 0.22 \# \\
(35.84 \%)\end{array}$ & $\begin{array}{l}3.3 \pm 0.12 \# \\
(37.50 \%)\end{array}$ \\
\hline A. echinops $(250 \mathrm{mg} / \mathrm{kg})+\mathrm{PCM}$ & $\begin{array}{c}1.0 \pm 0.07 \phi= \\
(-28.57 \%)\end{array}$ & $\begin{array}{c}6.7 \pm 0.14 * \# \\
(26.41 \%)\end{array}$ & $\begin{array}{c}2.8 \pm 0.07 \phi \\
(16.66 \%)\end{array}$ \\
\hline A. echinops $(500 \mathrm{mg} / \mathrm{kg})+\mathrm{PCM}$ & $\begin{array}{c}0.9 \pm 0.04 \phi \# \\
(-35.71 \%)\end{array}$ & $\begin{array}{c}6.9 \pm 0.16^{*} \# \\
(30.18 \%)\end{array}$ & $\begin{array}{c}3.0 \pm 0.15 *= \\
(25.00 \%)\end{array}$ \\
\hline A. logopodioides $(250 \mathrm{mg} / \mathrm{kg})+\mathrm{PCM}$ & $\begin{array}{l}1.2 \pm 0.06 \phi \\
(-14.28 \%)\end{array}$ & $\begin{array}{c}5.7 \pm 0.15 \phi \\
(7.54 \%)\end{array}$ & $\begin{array}{c}2.5 \pm 0.05 \phi \\
(4.16 \%)\end{array}$ \\
\hline A. logopodioides $(500 \mathrm{mg} / \mathrm{kg})+\mathrm{PCM}$ & $\begin{array}{c}1.0 \pm 0.05 \phi \\
(-28.57 \%)\end{array}$ & $\begin{array}{c}6.2 \pm 0.17 \phi= \\
(16.98 \%)\end{array}$ & $\begin{array}{c}2.8 \pm 0.10 \phi \\
(16.66 \%)\end{array}$ \\
\hline
\end{tabular}

Values explain the mean \pm S.E. of seven animals per group.

* $\mathrm{P}<0.05$ : Statistically significant from normal control (Dunnett's test).

$\phi \mathrm{P}<0.001$ : Statistically significant from normal control (Dunnett's test).

$-\mathrm{P}<0.05$ : Statistically significant from PCM-hepatotoxic control (Dunnett's test).

\# P< 0.001: Statistically significant from PCM-hepatotoxic control (Dunnett's test). 
PCM-intoxicated rats demonstrated the marked elevation in serum level of BRN and decrease in TP and ALB values in comparison with the normal control group. A. echinops $(250$ and $500 \mathrm{mg} / \mathrm{kg}$ ) and A. logopodioides (500 $\mathrm{mg} / \mathrm{kg}$ ) pre-medications, significantly decreased the level of BRN and increased the levels of TP and ALB in serum compared to the PCM-treated group (Table 2).

\section{The effects on PCM-induced oxidative stress}

Table 3: Effect of A. echinops and A. logopodioides extracts on PCM-induced oxidative stress in rats.

\begin{tabular}{|c|c|c|c|c|}
\hline Treatments & $\begin{array}{c}\text { SOD } \\
\text { (U/mg protein) }\end{array}$ & $\begin{array}{c}\text { CAT } \\
\text { (U/mg protein) }\end{array}$ & $\begin{array}{c}\text { GPx } \\
\text { (U/mg protein) } \\
\end{array}$ & $\begin{array}{c}\text { GSH } \\
(\mu \mathrm{mol} / \mathrm{g} \text { tissue })\end{array}$ \\
\hline Normal Control & $49.3 \pm 1.97 \#$ & $14.2 \pm 0.62 \#$ & $3.11 \pm 0.18 \#$ & $14.4 \pm 0.87 \#$ \\
\hline PCM-hepatotoxic Control & $\begin{array}{c}26.7 \pm 0.85 \phi \\
(-45.84 \%)\end{array}$ & $\begin{array}{l}7.3 \pm 0.35 \phi \\
(-48.59 \%) \\
\end{array}$ & $\begin{array}{c}1.10 \pm 0.10 \phi \\
(-64.63 \%)\end{array}$ & $\begin{array}{l}7.9 \pm 0.35 \phi \\
(-45.13 \%) \\
\end{array}$ \\
\hline Silymarin $(100 \mathrm{mg} / \mathrm{kg})+\mathrm{PCM}$ & $\begin{array}{c}44.2 \pm 1.66 \# \\
(65.54 \%)\end{array}$ & $\begin{array}{l}12.9 \pm 0.79 \# \\
(76.71 \%)\end{array}$ & $\begin{array}{l}2.87 \pm 0.15 \# \\
(160.90 \%)\end{array}$ & $\begin{array}{c}12.3 \pm 0.63 \# \\
(55.69 \%)\end{array}$ \\
\hline A. echinops $(250 \mathrm{mg} / \mathrm{kg})+\mathrm{PCM}$ & $\begin{array}{c}35.8 \pm 0.71 \phi \# \\
(34.08 \%)\end{array}$ & $\begin{array}{c}9.8 \pm 0.41 \phi \# \\
(34.24 \%)\end{array}$ & $\begin{array}{c}2.05 \pm 0.14 \phi \# \\
(86.36 \%)\end{array}$ & $\begin{array}{l}9.5 \pm 0.44 \phi= \\
(20.25 \%)\end{array}$ \\
\hline A. echinops $(500 \mathrm{mg} / \mathrm{kg})+\mathrm{PCM}$ & $\begin{array}{c}35.8 \pm 0.85 \phi \# \\
(34.08 \%)\end{array}$ & $\begin{array}{c}10.5 \pm 0.55 * \# \\
(43.83 \%)\end{array}$ & $\begin{array}{c}2.32 \pm 0.20 * \# \\
(110.90 \%)\end{array}$ & $\begin{array}{c}10.7 \pm 0.58^{*} \\
(35.44 \%)\end{array}$ \\
\hline $\begin{array}{l}\text { A. logopodioides }(250 \mathrm{mg} / \mathrm{kg}) \\
+\mathrm{PCM}\end{array}$ & $\begin{array}{l}29.0 \pm 0.68 \phi \\
(8.61 \%)\end{array}$ & $\begin{array}{l}8.7 \pm 0.57 \phi \\
(19.17 \%)\end{array}$ & $\begin{array}{l}1.41 \pm 0.12 \phi \\
(28.18 \%)\end{array}$ & $\begin{array}{l}8.5 \pm 0.45 \phi \\
(7.59 \%)\end{array}$ \\
\hline $\begin{array}{l}\text { A. logopodioides }(500 \mathrm{mg} / \mathrm{kg}) \\
+\mathrm{PCM}\end{array}$ & $\begin{array}{c}32.4 \pm 0.72 \phi \# \\
(21.34 \%)\end{array}$ & $\begin{array}{l}9.9 \pm 0.49 \phi \\
(35.61 \%)\end{array}$ & $\begin{array}{c}1.83 \pm 0.13 \phi \\
(66.36 \%)\end{array}$ & $\begin{array}{l}9.9 \pm 0.50 * . \\
(25.31 \%)\end{array}$ \\
\hline
\end{tabular}

Values explain the mean \pm S.E. of seven animals per group.

$* \mathrm{P}<0.05$ : Statistically significant from normal control (Dunnett's test).

$\phi \mathrm{P}<0.001$ : Statistically significant from normal control (Dunnett's test).

$-\mathrm{P}<0.05$ : Statistically significant from PCM-hepatotoxic control (Dunnett's test).

$\# \mathrm{P}<0.001$ : Statistically significant from PCM-hepatotoxic control (Dunnett's test).

As recorded in Table 3, the overdose of PCM induced oxidative stress with a marked decrease in the activities of liver SOD (45.84\%), CAT (48.59\%) and GPx (64.63\%) as compared to the normal control. The liver content of GSH was reduced by $45.13 \%$ compared to the normal group. In addition, the level of MDA in the liver homogenate was increased by $175.63 \%$ in comparison to the normal control group (Figure 1).

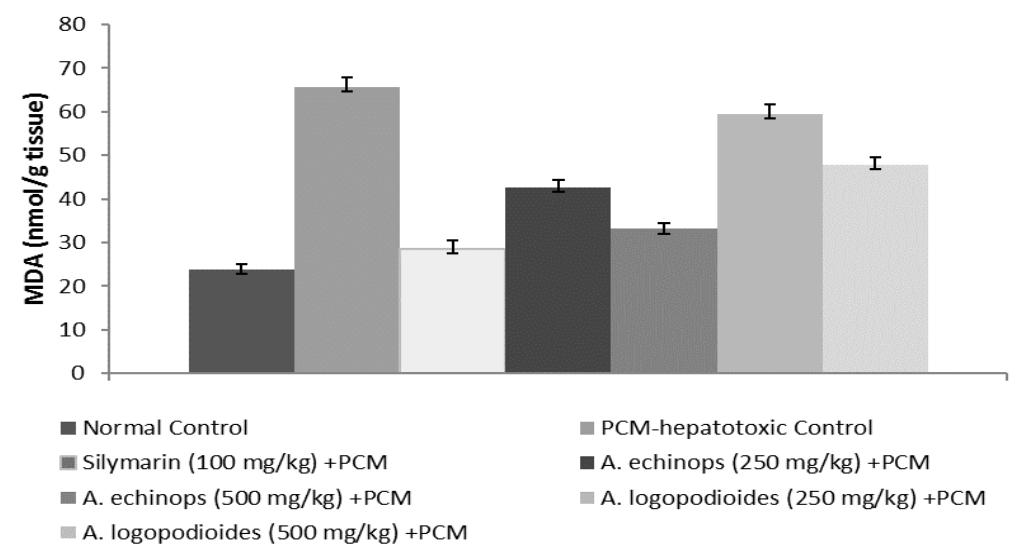

Figure 1: Effect of A. echinops and A. logopodioides extracts on lipid peroxidation (MDA) in liver homogenate of rats with PCM- induced hepatotoxicity.

Prior medication with A. echinops at 250 and $500 \mathrm{mg} / \mathrm{kg}$ and $A$. logopodioides at $500 \mathrm{mg} / \mathrm{kg}$ extracts, however, reduced the oxidative stress, as evidenced by significantly increased SOD, CAT and GPx activities in liver tissues when compared with those of PCM-intoxicated rats. Both extracts protected the liver tissues against GSH depletion compared to PCM treated rats. Furthermore, pre-treatment with A. echinops and A. logopodioides reduced liver MDA contents than the PCM group.

\section{Histopathological study}

The histopathological study added a supportive confirmation for biochemical analysis. Sections from the liver of the normal rats showed normal lobular architecture and normal hepatocytes with well-preserved cytoplasm (Figure 2-A). On the other hand, PCM treated group showed congestion, severe necrotic changes, inflammatory cell infiltration in many areas (Figure 2-B). The deleterious effects of PCM against hepatocytes were reduced remarkably when pretreated with $A$. echinops extract $(250 \mathrm{mg} / \mathrm{kg})$. Treatment with $A$. echinops extract at $500 \mathrm{mg} / \mathrm{kg}$ showed marked liver 
protection against PCM hepatotoxicity, which is manifested by the presence of normal liver cells and reduced inflammatory infiltration and necrosis (Figure 2-C). Pretreatment with A. logopodioides $(500 \mathrm{mg} / \mathrm{kg}$ ) showed parenchyma preservation of hepatocytes with mild necrosis and inflammation (Figure 2-D).

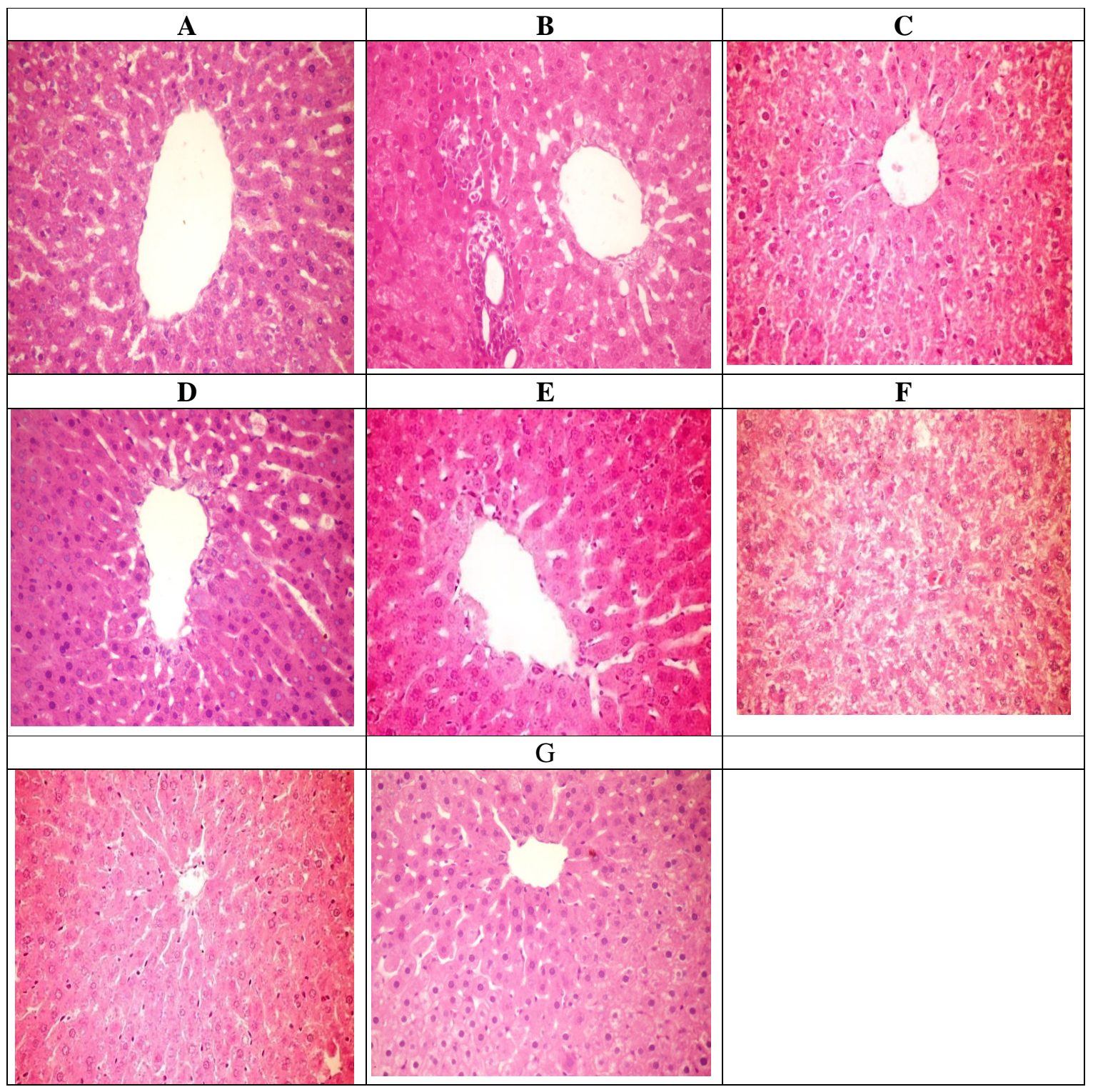

Figure 2: Photomicrographs of rat liver (H \& E stain) under low power (X400), (A) Normal control group; (B) PCMhepatotoxic group; (C) Silymarin $(100 \mathrm{mg} / \mathrm{kg})+$ PCM; (D) A. echinops $(250 \mathrm{mg} / \mathrm{kg})+\mathrm{PCM}$; (E) A. echinops (500 $\mathrm{mg} / \mathrm{kg})+\mathrm{PCM}$ ( $\mathrm{F}) ;$ A. logopodioides $(250 \mathrm{mg} / \mathrm{kg})+\mathrm{PCM} ;(\mathrm{G})$ A. logopodioides $(500 \mathrm{mg} / \mathrm{kg})+\mathrm{PCM}$.

\section{In vitro antioxidant activity}

The A. echinops and A. logopodioides extracts showed in vitro antioxidant effects in the DPPH assay in a concentration-dependent way, as illustrated in Figure 3. At concentrations of 625, 2500 and $10000 \mu \mathrm{g} / \mathrm{mL}$, the scavenging activities of $A$. echinops were $22.9,49.2$ and $75.7 \%$, respectively while those of A. logopodioides were 11.8, 31.5 and $76.3 \%$, respectively. The $\mathrm{EC}_{50}$ values for A. echinops, A. logopodioides, ascorbic acid, and pyrogallol were calculated to be $2348,4196,75.62$ and $0.0000248 \mu \mathrm{g} / \mathrm{mL}$, respectively. 


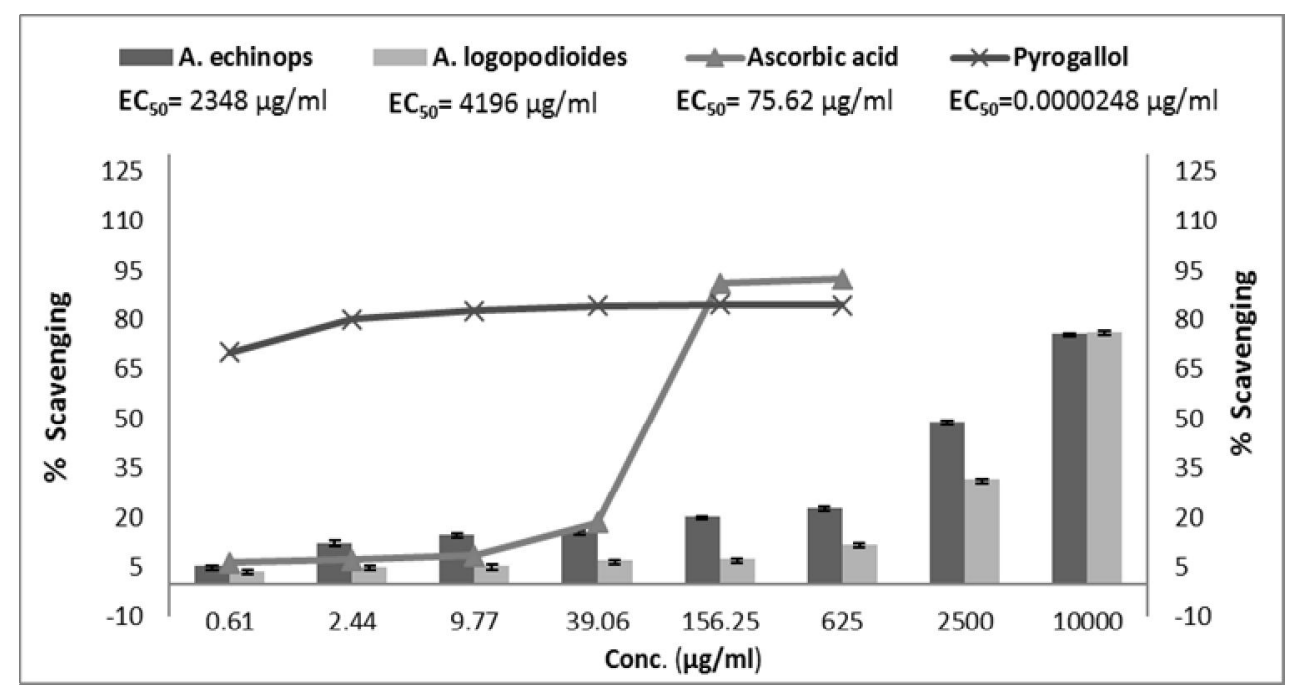

Figure 3: In vitro, antioxidant activity of A. echinops and A. logopodioides extracts using DPPH radical scavenging activity method.

\section{Discussion \\ Acute toxicity study}

Assessment of toxicity potential is usually the initial step in the inspection of the pharmacological activities of chemicals and plants. In this study, a dose of $5000 \mathrm{mg} / \mathrm{kg}$ of $A$. echinops and A. logopodioides extracts had no adverse effect in rats and none of the animals died during 14 days of observation. LD50 of the tested extracts was calculated to be $>5000 \mathrm{mg} / \mathrm{kg}$ in rats. Generally, the lower the LD50 value, the higher toxic the compound and vice versa. According to the chemical labeling and classification of acute systemic toxicity recommended by OECD, A. echinops and A. logopodioides extracts were assigned class 5 status (LD50>5000 mg/kg), which was the lowest toxicity class. According to the study by Kennedy et al. (1986), materials having oral LD50 values more than $5000 \mathrm{mg} / \mathrm{kg}$ are considered as being safe or practically nontoxic.

\section{Hepatoprotective activity}

Elevated serum levels of liver marker enzymes (ALT, AST, ALP, and $\gamma$-GT) are believed to be a significant marker of PCM-induced hepatotoxicity (Thapa and Walia, 2007). The increases in the liver enzymes activities are roughly proportional to the extent of tissue damage (Nwaehujor et al., 2011). In our study, the elevation of liver marker enzymes in serum following an overdose of PCM could be referred to the injured hepatic cells as these enzymes are located in the cytoplasm and are leaked into the blood following hepatic cell injuries. A. echinops and A. logopodioides protected the liver against the damage induced by PCM as demonstrated by the decrease in serum levels of liver marker enzymes with the consequent restoration of serum BRN, TP, and ALB when compared with the alone PCM-intoxicated rats. The observed hepatoprotective effect might be a consequence of the amelioration of oxidative stress and maintenance of the antioxidant capacity conferred by both extracts. This suppresses the leakage of ALT, AST, ALP and $\gamma$-GT enzymes into blood circulation. Moreover, the mechanism by which A. echinops and A. logopodioides extracts lowered serum levels of liver enzymes may be attributed to their ability to inhibit the cytochrome P450 so reduce the production of the reactive metabolites of PCM.

Serum BRN is considered as one of the most sensitive tests of liver functions. The elevated serum levels of $\mathrm{BRN}$ is an indication of biliary obstruction, liver damage and amendments in binding, conjugation and excretory capacity of hepatocytes (Pawlikowska-Pawlega et al., 2007). Our observation of increased level of serum BRN in alone PCM-intoxicated rats indicates PCM-induced hepatic damage. A. echinops and A. logopodioides extracts reduced the high levels of BRN as a result of PCM overdose, thus forced liver to function normally. On the other hand, the reduction in BRN level with concurrent elevation in the TP and ALB contents suggest the stabilization of biliary function as well as repair of damaged liver tissue of rats exposed to PCM (Gini and Muraleedhara, 2010).

The liver is the main source of most of the blood proteins as the hepatocytes are responsible for the synthesis of ALB, fibrinogen and most of the $\alpha$ - and $\beta$-globulins (Pawlikowska-Pawlega et al., 2007). Therefore, the variation of serum TP or ALB levels can reflect liver health status. Our study demonstrated that the values of TP and ALB in serum were significantly reduced by PCM overdose. The significant reduction in TP and ALB levels in PCM-intoxicated rats could be a result of a decrease in the number of hepatocytes responsible for the synthesis of ALB through necrosis or might be due to the functional failure of endoplasmic reticulum of hepatocytes (Ravikumar et al., 2010). The significant increase in the TP and ALB levels because of A. echinops and A. logopodioides medications suggested the stabilization of the endoplasmic reticulum that is responsible for the synthesis of protein. This assures the protective activity of both extracts against PCM-hepatotoxicity. 
Oxidative stress is reported to represent the main mechanism in the pathogenesis of PCM-induced hepatotoxicity in experimental animals (Du et al., 2016). Liver proteins, lipids, and DNA are among the cellular structures that are mostly influenced by reactive oxygen species (ROS). However, cells have several mechanisms to keep themselves against the adverse effects of free radicals generated by PCM and other toxicants. Among the various antioxidant enzymes, SOD, CAT, and GPx, act as important enzymes in the elimination of free radicals. The oxidative stress gives rise to toxicity when the rate of free radical generation outweighs the cell's ability for their removal. Monitoring of the activities of antioxidant enzymes, GSH and LPO in terms of malondialdehyde (MDA) in biological samples are widely used to determine the state of oxidative stress.

The hepatocellular injury that induced by PCM overdose has been documented by a number of studies (Johnkennedy and Adamma, 2011 and Soliman et al., 2013). In our study, PCM overdose induced a marked reduction in the activities of the antioxidant enzymes in liver homogenate. Gupta et al (2004) mentioned that many of the clinically useful drugs could induce cellular injury through their metabolic activation to highly reactive compounds such as free radicals. In this respect, the liver damage induced by PCM has been attributed to the generation of NAPQI, which is a highly reactive metabolite (Vermeulen et al., 1992). Accumulation of NAPQI encourages overproduction of free radicals such as superoxide radical anions, which are responsible for mediating cellular toxicity and liver damage (Singh et al., 2011).

Results of the present study indicated that pre-administration of A. echinops and A. logopodioides extracts had effectively restored the activities of antioxidant enzymes in the livers of PCM-overdosed rats. Improvement in the activities of these enzymes does provide evidence to an overall improvement in the endogenous antioxidant defense system (Hemabarathy et al., 2009). Therefore, the hepatoprotective effect of both extracts could relate to their ability to maintain the SOD, CAT, and GPx activities in livers of PCM overdosed rats.

GSH is the main non-enzymatic antioxidant that is responsible for the major defense mechanism during oxidative stress. At nontoxic dose, the reactive metabolites of PCM were efficiently detoxified by the sulfhydryl (SH) group of GSH forming the paracetamol-GSH conjugate. However, at toxic doses, NAPQI depleted intrahepatic GSH stores by as much as $80-90 \%$ and subsequently bound to intracellular proteins leading to hepatocellular necrosis (Fontana, 2008). As demonstrated in our findings, a significant decline in hepatic GSH levels in PCM-treated rats is an indication of tissue damage produced by free radicals. The depletion of cellular GSH leaves the cell vulnerable to oxidative stress following PCM overdose. In our study, both extracts preserved the GSH contents in the livers of PCMoverdosed rats. This indicates the antioxidant potential of A. echinops and A. logopodioides extracts against PCMinduced oxidative stress in rat liver. Hence, we can speculate that the tested extracts may induce the synthesis of endogenous GSH, which protects against PCM-induced oxidative damage.

Lipid peroxidation (LPO) is one of the characteristic features of oxidative stress in PCM hepatotoxicity. According to Luqman and Rizvi (2006), LPO is known to injure the cells by inactivation of membrane enzymes, decrease fluidity of the membrane and resolve into cytotoxic aldehydes such as MDA. Kanbur et al. (2009) have reported LPO products to elevate in the hepatocytes of PCM-induced hepatotoxicity in mice. In our study, PCMinduced LPO was confirmed by the elevation in the hepatic level of MDA. The elevated level of hepatic MDA has been regarded as an indicator of cellular damage and indicates the inability of the antioxidant defense system to protect against the production of excessive free radicals. The present results showed that A. echinops and A. logopodioides extracts ameliorated the increased liver MDA contents of PCM-intoxicated rats toward normalcy. The enhanced antioxidant defense in addition to reduced LPO product in the liver is indicative for the antioxidant effect of the tested extracts. The ability of our extracts to prevent LPO is in agreement with Soliman et al. (2013), who reported that two of the Astragalus plants (A. persicus and A. tournefortii) possess remarkable LPO inhibition activity.

The capability of A. echinops and A. logopodioides extracts to protect against PCM-induced hepatic damage in rats could be related to their phyto-components. The genus Astragalus is well documented by Bagheri et al., (2015) as a source of biologically active compounds such as phenolics, triterpenoid saponins, flavonoids, and polysaccharides. The flavonoid mixture and polysaccharides of some Astragalus plants are known to have a strong antioxidant effect (Ivancheva et al., 2006). In addition, phenols, saponins, and triterpenes have been reported to exert several actions including antioxidant and hepatoprotective activities (Liu et al., 2015). Therefore, we believe that the possible mechanism of hepatoprotection offered by A. echinops and A. logopodioides extracts is due to their phyto-components as phenolics, triterpenoid saponins, flavonoids, and polysaccharides.

The histopathological findings supported the biochemical results. As demonstrated in this study, rats exposed to PCM alone showed severe cellular damage that might be due to the production of free radicals by PCM and subsequent LPO. Many studies demonstrated the induction of necrosis of hepatic cells by high doses of PCM in animals (Dash et al., 2007). These histopathologic findings were ameliorated significantly in the group of rats that were pre-treated with either A. echinops or A. logopodioides extract in a dose-dependent pattern indicating pronounced protection of hepatocytes against PCM induced hepatic damage. It can be referred to the antioxidant effect of the tested extracts that markedly decreased the oxidative stress and thereby reduced the histopathological alterations of the liver.

\section{In vitro antioxidant activity}

Many natural antioxidants have been found in plants, which oftentimes keep potent free radical scavenging activities. The scavenging ability of DPPH free radical is exceedingly used to confirm the antioxidant potential of plant extracts. It is considered that the role of antioxidants in protection against diseases is due to their capability to scavenge free radicals in the biological systems. A. echinops and A. logopodioides extracts showed in vitro antioxidant effect in a 
concentration-dependent way. In a similar study, one of the Astragalus plants; A. squarrosus, showed free radical scavenging activity with the DPPH method which might be due to its phenolic and flavonoid constituents (Asgarpanah et al., 2011). Moreover, Yeom et al., (2003) mentioned that the antioxidant capacity of different extracts of Astragalus sinicus, measured by DPPH assay is highly correlated to their total phenolic content. The antioxidant effect of phenolic compounds is mostly due to their redox characteristics, which allow them to function as hydrogen donators, reducing agents and oxygen quenchers (Huang et al., 2010). Accordingly, our results suggested that the in vitro antioxidant activity of both extracts is due to their phenolic and flavonoid contents as the phenolic and flavonoid compounds are among the most important constituent of the genus Astragalus (Bagheri et al., 2015).

The effectiveness of the in vitro antioxidant properties of a compound is inversely correlated with its EC50 value. In this respect, Lee et al. (2008) stated that EC50 value of less than $10 \mathrm{mg} / \mathrm{mL}$ indicates that the extract is an effective antioxidant. In our investigation, the EC50 values of A. echinops and A. logopodioides extracts were less than $10 \mathrm{mg} / \mathrm{mL}$ that confirm the effectiveness of both extracts as antioxidants.

\section{Conclusion}

It could be concluded that oral administration of $A$. echinops and A. logopodioides before PCM overdose possess a potentials antioxidant activity to restore the liver antioxidants stores of PCM-overdosed rats. They have also protective activities against PCM-induced hepatic injuries probably due to their antioxidant effects. Together, the absence of toxicity and supportive evidence of their antioxidant properties may suggest the potential application of $A$. echinops and A. logopodioides as alternative antidotes against the ailments where liver antioxidants store is compromised and/or hepatic damage is manifested. Additional phytochemical studies are in progress to separate and characterize the active compound(s) responsible for the antioxidant and hepatoprotective activities.

\section{Acknowledgment}

The authors are thankful to Deanship of Scientific Research (DSR), Prince Sattam bin Abdulaziz University, Al-Kharj, Saudi Arabia for providing the fund to carry out this study under research grants No. 2015/03/4033.

Conflicts of Interest: The authors declare that this research presents no conflicts of interest.

\section{References}

1. Asgarpanah, J., S. Motamed, A. Farzaneh, B. Ghanizadeh and S. Tomraee, 2011. Antioxidant activity and total phenolic and flavonoid content of Astragalus squarrosus Bunge. Afr. J. Biotechnol., 10: 19176-19180.

2. Bagheri, S., L. Keyhani, M. Heydari and H. Dashti, 2015. Antinociceptive activity of Astragalus gummifer gum (gum tragacanth) through the adrenergic system: An in vivo study in mice. J. Ayurveda Integr. Med., 6: 19-23.

3. Benchadi, W., Haba, H. and Lavaud, C. (2013). Secondary metabolites of Astragalus cruciatus Link.and Their Chemotaxonomic Significance. Rec. Nat. Prod., 7: 105-113.

4. Das, J., J. Ghosh, P. Manna and P.C. Sil, 2010. Taurine protects acetaminophen-induced oxidative damage in mice kidney through APAP urinary excretion and CYP2E1 inactivation. Toxicology, 269: 24-34.

5. Dash, D., V. Yeligar, S. Nayak, T. Ghosh, D. Rajalingam, P. Sengupta, B. Maiti and T. Maity, 2007. Evaluation of hepatoprotective and antioxidant activity of Ichnocarpus frutescens (Linn.) R.Br. on paracetamol-induced hepatotoxicity in rats. Trop. J. Pharm. Res., 6: 755-765.

6. Du, K., A. Ramachandran and H. Jaeschke, 2016. Oxidative stress during acetaminophen hepatotoxicity: Sources, pathophysiological role and therapeutic potential. Redox Biol., 10: 148-156.

7. Fontana, R., 2008. Acute Liver Failure including Acetaminophen Overdose. Med. Clin. North Am., 92: 761-794.

8. Gini, K. and K. Muraleedhara, 2010. Hepatoprotective effect of Spirulina lonar on paracetamol induced liver damage in rats. Asian J. Exp. Biol. Sci., 1: 614-623.

9. Gupta, M., U.K. Mazumder, S.T. Kumar, G. Periyasamy and S.R. Kumar, 2004. Antioxidant and Hepatoprotective Effects of Bauhinia racemosa against Paracetamol and Carbon Tetra-chloride Induced Liver Damage in Rats. Iran. J. Pharm. Therap., 3: 12-20.

10. Handa, S.S., A. Sharma and K.K. Chakraborty, 1989. Natural products and plants as liver protecting drugs. Fitoterapia, 57: 307-351.

11. Hemabarathy, B., S.B. Budi nans V. Feizal, 2009. Paracetamol hepatoxicity in rats treated with crude extract of Alpinia galanga. J. Biol. Sci., 9: 57-62.

12. Hinson, J., D. Roberts and L. James, 2010. Mechanisms of Acetaminophen-Induced Liver Necrosis. Handb. Exp. Pharmacol., 196: 369-405.

13. Huang, W.Y., Y.Z. Cai and Y. Zhang, 2010. Natural phenolic compounds from medicinal herbs and dietary plants: potential use for cancer prevention. Nutr. Cancer, 62: 1-20.

14. Ivancheva, S., M. Nikolova and R. Tsvetkova, 2006. Pharmacological activities and biologically active compounds of Bulgarian medicinal plants. Phytochemistry Advances in Research: 87-103.

15. Johnkennedy, N. and E. Adamma, 2011. The protective role of Gongronema latifolium in acetaminophen induced hepatic toxicity in Wistar rats. Asian Pac. J. Trop. Biomed., S151-S154. 
16. Kanbur, M., G. Eraslan, L. Beyaz, S. Silici, B.C. Liman and S. Altinordulu, 2009. The effects of royal jelly on liver damage induced by paracetamol in mice. Exp. Toxicol. Pathol., 61:123-32.

17. Kennedy, G., Ferenz, R., Burgess, B. (1986). Estimation of acute oral toxicity in rats by determination of the approximate lethal dose rather than the LD50. J. Appl. Toxicol. 6: 145-148.

18. Lee, Y., Jian, S., Lian, P., Mau, J. (2008). Antioxidant properties of extracts from a white mutant of the mushroom Hypsizigus marmoreus. J. Food. Compos. Anal. 21: 116-124.

19. Liu, Y., Bao, L., Xuan, L., Song, B., Lin, L., Han, H. (2015). Chebulagic acid inhibits the LPS-induced expression of TNF- $\alpha$ and IL-1 $\beta$ in endothelial cells by suppressing MAPK activation. Exp. Ther. Med. 10: 263-268.

20. Luqman, S., Rizvi, S.I. (2006). Protection of lipid peroxidation and carbonyl formation in proteins by capsaicin in human erythrocytes subjected to oxidative stress. Phytother. Res. 20: 303-306.

21. Nwaehujor, C.O., Ode, O.J., Okoyie, D.N. (2011). The hepatoprotective effect of Senna occidentalis methanol leaf extract against acetaminophen induced hepatic damage in rats. J. Pharmacol. Toxicol. 6: 637-646.

22. OECD (2001). OECD guideline for testing of chemicals: Acute oral toxicity-acute toxic class method. Guideline No. 423, Organization for Economic Co-operation and Development, December 17, pp: 1-14.

23. Pawlikowska-Pawlega, B., Gruszecki, W.I., Misiak, L., Paduch, R., Piersiak, T., Zarzyka, B. (2007). Modification of membranes by quercetin, a naturally occurring flavonoid, via its incorporation in the polar head group. Biochim. Biophys. Acta. 1768: 2195-204.

24. Phang, C., Abd Malek, S., Ibrahim, H., Abdul Wahab, N. (2011). Antioxidant properties of crude and fractionated extracts of Alpinia mutica rhizomes and their total phenolic content. Afr. J. Pharm. Pharmaco. 5: 842-852.

25. Pistelli, L. (2002). Secondary metabolites of genus Astragalus: Structure and biological activity. In: Atta-UrRahman, editor. Studies in Natural Products Chemistry (Bioactive Natural Products, Part H) Amsterdam: Elsevier Science 443-545.

26. Pistelli, L., Giachi, I., Lepori, E., Bertoli, A. (2003). Further saponins and flavonoids from Astragalus verrucosus Moris. Pharm. Biol. 41: 568-572.

27. Podlech, D. (2008). The genus Astragalus L. (Fabaceae) in Europe with exclusion of the former Soviet Union. Feddes Repert. 119: 310-387.

28. Ravikumar, S., Gnanadesigan, M., Seshserebiah, J., Jacob, S. (2010). Hepatoprotective effect of an Indian salt marsh herb Suaeda monoica Forsk. Ex. Gmel against concanavalin: an induced toxicity in rats. Life Sciences and Medicine Research 2010: LSMR-2.

29. Singh, S., Singh, K., Kumar, M., Chandra, K., Singh, R. (2011). Ameliorative Potential of Quercetin Against Paracetamol-induced Oxidative Stress in Mice Blood. Toxicol. Int. 18: 140-145.

30. Soliman, G., Abdel-rahman, R., Al-saikhan, F., Alankuş-çalişkan, O., Alqasoumi, S., Yusufoglu, H. (2013). Hepatoprotective activities of Astragalus persicus and Astragalus tournefortii ethanolic extracts against paracetamol induced liver damage in rats and their in vitro antioxidant effects. FABAD J. Pharm. Sci. 38: 1-9.

31. Thapa, B., Walia, A. (2007). Liver function tests and their interpretation. Indian J. Pediatr. 74: 663-71.

32. Vermeulen, N.P., Bessems, J.G., Van de streat. R. (1992). Molecular aspects of paracetamol-induced hepatotoxicity and it mechanism based prevention. Drug Metab. Rev. 24: 367-407.

33. Yeom, S.H., Kim, M.K., Kim, H.J., Shim, J.G., Lee, J.H., Lee, M.W. (2003). Phenolic compounds from seeds of Astragalus sinicus and its antioxidative activities. Saengyak Hakhoechi 34: 344-51. 